\title{
THE DEVELOPMENT OF MOTIVATION RESEARCH IN EDUCATIONAL PSYCHOLOGY: THE TRANSITION FROM EARLY THEORIES TO SELF-RELATED APPROACHES
}

\author{
Saeed Safdari \\ Department of English, Science and Research Branch, Islamic Azad University, Tehran, Iran \\ saeed_safdari@yahoo.com \\ Parviz Maftoon \\ (Corresponding author) \\ Department of English, Science and Research Branch, Islamic Azad University, Tehran, Iran \\ pmaftoon@srbiau.ac.ir
}

\begin{abstract}
Motivation has been one of the earliest concepts of interest in general and educational psychology. Learning is mediated by individuals' reasons and choices to do something or to abstain from it. The current paper is an attempt to summarise and review the development of motivation theories, models and frameworks within educational psychology. It specifically focuses on the emergence of self-related theories in motivation research. The earlier trends and theories such as expectancy-value theories, goal theories, and attribution theories are briefly described and the influential scholars who contributed to these theoretical developments are introduced. Then, the theoretical transition to self-related theories of motivation is highlighted. A general review of self-worth, selfdetermination and self-efficacy theories that stemmed from the concept of self is also provided.
\end{abstract}

Keywords: motivation; educational psychology; goal theories; self-related theories.

\section{Introduction}

Early theories of motivation in mainstream psychology stemmed from work with animals and later experiments with humans in laboratory and clinical settings. The earliest known scientific attempts were done in the realm of behaviourist psychology. Behaviourists explained motivation with concepts such as reward and incentive. Behaviourists claimed that the behaviour of an organism can be controlled by environmental stimuli and events. If an organism is consistently reinforced by rewards and positive incentives for certain behaviour, it could develop habits or tendencies to act in a certain way (Woolfolk, Winnie, \& Perry, 2003).

Humanistic psychologist Abraham Maslow and Carl Rogers provided a different perspective. According to their view, human beings are influenced by an inherent need to fulfil their capabilities and potentialities to reach self-actualization. Instincts, drives, or external stimuli are considered ineffective in determining behaviour. Therefore, motivating a learner means stimulating his/her inner resources and teachers must provide learners with ample opportunities, choices and encouragement (Schunk, 2012). Maslow (1970) suggested that people have a hierarchy of needs. These needs stretch from lower-order or deficiency needs (physiological, safety, belongingness, and esteem) to higher-order or being needs (knowing and understanding, aesthetic appreciation, and self-actualization). The final need (self-actualization) is the ultimate motivational force that characterises the desire of people to reach their potentialities in every aspect of life (Woolfolk et al., 2003).

The third category of psychological motivation theories is concerned with cognitive approaches to motivation. Proponents of the cognitive theories maintain that behaviour is determined by thinking and mind. They believe that motivation is an internal process whereby individuals interpret events and conditions and then actively decide to take the most appropriate course of action. Such interpretations are based on their anticipation of outcomes, setting goals, mental planning, attribution, and schemas (Pintrich \&Shcunk, 1996; Shcunk, 1996).

Sociocultural views give a more social interpretation of motivation. According to Greeno, Collins, and Resnick (1996), sociocultural conceptions of motivation depict motivation as individuals' attempts to maintain their identities and interpersonal relationships within a community. They engage in activities within a community of practice to keep their membership in the related community. The motivation to initiate actions is stronger if the community values the target activity and esteems it. Therefore, in educational settings like school or classroom, students learn to invest more effort and sustain for a longer period of time if their classmates, peers and other members of the community encourage learning.

The current article discusses various theories of motivation within the mainstream motivation research. It includes two main parts. First, some key theories of motivation in educational psychology are presented. These are expectancy-value theories, attribution theory, and goal theories. Then, the concept of self and the 
self-based theories of motivation are reviewed. These include self-efficacy theory, self-worth theory, and self-determination theory.

\section{Major Motivation Theories in Educational Psychology}

\section{Expectancy-Value Theories}

Expectancy-value theories of motivation stemmed from a cognitive view of human behaviour. Some theorists in this field (e.g., Atkinson, 1957; Wigfield, 1994; Wigfield \& Eccles, 1992) argued that there are two important factors that can explain choices made by individuals. They are their expectation of success in a certain task and the value which they attach to the final goal or presumed achievement (Wigfield \& Tonks, 2002).

An early model within the expectancy-value framework was achievement motivation theory developed by Atkinson (1957). His theory suggested that observed behaviour was the culmination of three elements working together: the need for achievement, the probability of success (based on judgment about one's own competence), and incentive value (based on judgment about value). However, probability of success and incentive value seemed to play a more significant role in motivation (realised as individuals' choice of tasks according to difficulty). Atkinson's model was criticised for its inadequacy in explaining the successes of some failure-threatened individuals who managed to outperform their success-oriented peers (Kuhl, 2001). Also, this theory is outcome-based and assumes that motivation is innate and is mainly based on the outcomes of the activity and not on external factors that may influence the individuals during performance. As a result, important factors such as the role of the teacher or the educational context are neglected in the theory (Kuhl and Blankenship, 1979).

A more recent expectancy-value model has been developed and updated several times by Eccles and her colleagues (Eccles, 2007; Wigfield, 1994; Eccles \& Wigfield, 2002). They developed a comprehensive model to explain task value, which addresses the importance of the task process. This theory includes four elements:

1. Attainment value emphasising the importance of the successful completion of a task or activity.

2. Intrinsic value referring to the enjoyment that is gained from accomplishing a given task or activity in an acceptable way.

3. Utility value concerning the way in which a task fits into the current and future plans of an individual.

4. Cost concerning the investment required to make the decision to do the task. For example, an individual might engage in a task which takes time and effort and may cause anxiety.

This theory is based on more personalised motivating factors addressing individual needs and goals in the present and future. Brophy (2004), tried to adopt this model in educational settings by suggesting that the task theory model could be employed if the cognitive aspects of learning the academic content are emphasised more. His suggestion insinuates that while this theory is useful in general, other academic factors such as the need for educational achievement must be taken into consideration.

The contemporary model, according to Wigfield \& Eccles, (2002), considers social factors such as culture, personal beliefs, environmental issues and past experiences for affecting the types of cognitive processes and motivational beliefs that students possess.

\section{Attribution Theory}

Attribution theory relies on the perceived causes of achievement as the main motivational factors. The theory is associated with the works of Weiner $(1985,1992)$. He believed that motivation and future behaviour are based on individuals' explanations of their past successes or failures. It was suggested that there is a cause-effect relationship between past experiences and an individual's motivation to initiate future actions (Schunk, 2012).

Attribution theory focuses on the effect of attributions on individuals' anticipation of outcomes with regard to subsequent endeavours. The expectations will give rise to emotions that determine motivation. Hence, attribution theory resembles expectancy-value theories. However, it is well distinguished by its cognitive approach to emotions, and the prominence it gives to them (Hareli \& Weiner, 2002).

Within this theory, three casual features of motivation are identified. They are locus, stability and controllability. Locus is concerned with the location of a cause; it can be described as internal or external to the individual. When success is attributed to an internal cause (such as talent, smartness or ability), the individual experiences pride and heightened self-esteem. In upcoming situations, these positive feelings become motivators in their own right. On the other hand, failure attributed to internal reasons would bring 
about a decline in self-esteem. Such emotions are not experienced when success or failure are ascribed to external causes (Weiner, 1992).

Stability refers to the relative endurance of a cause over time. For instance, ability or intelligence might be regarded as stable factors, while intended effort, knowledge, and luck are considered unstable and temporary. Success attributed to ability is assumed to lead to positive emotions about the self and success in future attempts. Conversely, failure attributed to insufficient ability or skill is likely to result in expectancies of failure in subsequent situations. In contrast, if an individual ascribes his/her failure to unstable causes (particularly effort), he/she is likely to increase persistence in the future (Woolfolk et al., 2003).

Controllability (also called responsibility) indicates whether an individual can exercise control over the causes of success and failure (Weiner, 1985). People who believe they have little control over academic outcomes hold low expectations for success and display low motivation to succeed (Shcunk, 2012). Individuals who believe to have succeeded because of their own internally controllable causes, would feel proud. Those individuals who fail because of internally uncontrollable causes (like low intelligence) often experience shame and embarrassment. If individuals believe their failure resulted from externally uncontrollable factors (like social bias), would experience anger. Conversely, they would feel guilty if failure is attached to internally controllable causes (like lack of effort). As Woolfolk et al., (2003) stated, feelings of pride may lead to choosing more complex tasks and persisting longer, whereas feelings of guilt could cause increased effort and strategy use in future situations. Shame and embarrassment might result in depression and resignation to eternal defeat.

The first criticism to attribution targeted the assumed possibility to have attributions that are external to the individual, yet still controllable (Pintrich \& Schunk, 2002). The debate regards the agent who is able to control the causes of the attributions. It is difficult to align external and at the same time controllable factors. Besides, cross-cultural studies suggest that individuals from different cultures may vary in the way they classify attributions. Park and Kim (1999) found out that Asian learners are likely to ascribe their success to the social and familial support they receive, whereas they tend to connect their failure to insufficient personal effort.

\section{Goal Theories}

Goal theories generally assume that human beings are inherently active. Hence, such theories are not concerned with explaining the instigation of action, rather they tend to deal with the direction, intensity, and persistence to reach the goals (Brophy, 1999). Two general classes of goal theories are as follows: goal setting theory (concerned with the destination and characteristics of the target), and goal-orientation theory (concerned with the ways of approaching the goals).

\section{Goal setting Theory}

Goal setting theory is rooted in social cognitive theories. Social cognitive scholars contend that goals enhance learning and performance through their effects on perceptions of progress, self-efficacy, and selfevaluations (Bandura, 1997; Locke \& Latham, 2002). Bandura (1997), emphasised the significance of goal specificity, proximity and difficulty. Locke and Latham (2002) found that specific and difficult goals motivate people to do their best. Therefore, the major features of motivating goals are specificity and difficulty as they lead to persistence and improved performance (Locke \& Latham, 1990). Three factors are involved in setting effective goals. These factors include goal commitment, feedback, and task complexity. The set goals should be important and individuals should believe in their capability to achieve it (i.e. they should possess sufficient self-efficacy). Evaluation of progress (hence feedback) and complexity of tasks are also influential factors in goal setting (Locke \& Latham, 2002).

Locke and Latham (1990) believed that setting goals leads to goal-directed behaviour which is very effective in enhancing performance. First of all, goals direct attention to the tasks and activities and prevent distraction. Second, they mobilise efforts and channel energy. Besides, goals improve persistence and endurance. Finally, goals encourage creativity and strategic investment. People try different ways when they face problems in reaching the goals through older methods.

\section{Goal-orientation Theory}

Unlike goal setting, goal orientation theory is concerned with the questions why an individual may want to engage in a task and how he/she will approach the task (Schunk, 2012). From this point of view, goals are conceived to be internal, cognitive representations of what individuals want to do or achieve which guide individuals' behaviour in a particular direction (Elliott \& Thrash, 2001).

Goal-orientation theory distinguishes between two types of goal constructs: mastery orientation and performance orientation (Pintrich, 2000). Those who are mastery-oriented focus on the learning content and are motivated by their desire to improve and learn, whereas those individuals who are performance-oriented do the 
tasks in order to show their ability and receive positive judgment. They want to look smart and outdo others (Ames, 1992). Mastery goals encourage more effective strategies, more challenging tasks, and more positive attitudes. On the other hand, performance goals are associated with preoccupation with ego, attention seeking, preference of less challenging tasks (Wolters, Yu \& Pintrich, 1996). Therefore, it can be said that masteryorientated learners are more motivated to accomplish the task and are more likely to persist until they succeed. Yet, performance-oriented learners tend to evaluate themselves in terms of grades and achievement levels. They are more likely to deploy strategies to protect their self-worth (Butler \& Neuman, 1995).

Goal theory has offered a clear-cut framework for studying motivation and has been successful in linking individual competence with achievement in academic contexts. Nevertheless, it has been criticised for neglecting the crucial role of social goals (which are non-competence), competing goals and the possibility of active task-engagement for the sake of extrinsic rewards (Elliot \& McGregor, 2001; Lemos, 2001; Urdan \& Maehr, 1995).

\section{Self-related Theories}

The concept of the self has become a key component in theories of motivation in both educational psychology and L2 motivation research. Weiner $(1985$, p. 286) contended that "the self lies at the very core of human experience and must be part of any theoretical formulation in the field of human motivation". Pajares and Schunk (2002) stated that self, as a motivational concept, is dominating research and theory on academic motivation.

Schunk's (2012) definition says: "Self-concept refers to one's collective self-perceptions formed through experiences with, and interpretations of, the environment, heavily influenced by reinforcements and evaluations by significant other persons" (p. 384). According to Rubio (2014), self-concept defines individuality and predicts behaviour. It is associated with the beliefs about oneself and the images about one's past or future selves (Cantor, Markus, Niedenthal, \& Nurius, 1986). Similar to Schunk's definition, Oyserman, Bybee and Terry (2006) emphasised the role of social dimension in self-concept. In mainstream motivational research, there are a lot of models and theories looking at the relation between motivation and the self. The most important ones will be discussed here.

\section{Self-Worth Theory}

Self-worth theory is associated with the work of Covington (Covington, 1992, 2000). The theory basically assumes that human beings search for self-acceptance and positive appraisal of their personal value in terms of how competent they appear in achievement situations. Therefore, individuals are motivated to maintain a sense of personal worth by attaining success and avoiding failure (Covington, 1992).

In educational contexts, students define their own worth in the same way. As a result, they develop many defensive strategies to protect their sense of worth, in particular when they have doubts about their ability to achieve a task or activity. Covington (2000) believed that students employ 'self-worth protection', 'defensive pessimism', and 'self-handicapping' to protect themselves from negative implications.

Self-worth protection strategy includes withdrawing from efforts. Some students just decide not to try in order to provide themselves with an excuse or justification for failure. They could later feel relieved with the impression that their ability is not questioned. Defensive pessimism is a strategy by which individuals lower the expectations of others (peers, teacher) by expressing their reluctance or low competence before an activity.

The third strategy, self-handicapping, refers to highlighting some obstacles to the successful performance of the task. For instance, procrastination of studying for the exam and postponing the projects to the last minute, can help students to attribute their potential failure to factors other than ability (Covington, 1992).

Self-worth theory is based on perceptions of ability as the primary cause of motivation. Research shows that perceived ability is positively correlated with students' anticipation of success, achievement and motivation. Nevertheless, cross-cultural differences in terms of the link between effort and sense self-worth which questions the universality of the theory are found (Schunk, 2012).

\section{Self-Determination Theory}

Self-determination theory is one of the theories that has affected both the mainstream motivational theory and L2 motivation. Associated with Deci and his colleagues (Deci \& Moller, 2005; Deci \& Ryan, 1985, among others) this theory revitalised the older intrinsic/extrinsic dichotomy in a modern way. Extrinsic and intrinsic motivation are viewed as the two ends of a continuum which denotes different degrees of harmony between an individual's autonomous choice, and an externally prescribed behaviour. According to Deci and Moller (2005), the essential notion of this continuum is internalization which is defined as "an active process through which people engage their social world, gradually transforming socially sanctioned mores or requests into personally endorsed values and self-regulation" (p.589). 
As conceptualised by the theory, there are three basic psychological needs that should be met before an individual engages in action. The quality and type of generated motivation is said to depend on how these needs are satisfied (Deci \& Ryan, 1985). Even in educational settings, the social context of the classroom should satisfy these needs for students in order to promote their motivation. As stated by Deci and Ryan (2000), the needs include:

1. The need for competence which is related to the need to interact with the social environment, and the need to show one's capacities confidently and effectively.

2. The need for relatedness which refers to the need to a feeling of belongingness, respect, and being connected to significant others (friends, teacher, family).

3. The need for autonomy that pertains to a sense of personal desire and will to engage in an activity on one's own free choice.

Ryan and Deci (2000) postulated that humans are naturally and inherently motivated to engage in activities in their quest for self-determination. Satisfaction of the three basic needs can lead to the arousal of intrinsic motivation. Intrinsic motivation is believed to increase by the pleasure and enjoyment that an activity produces. Therefore, when engaging in an activity makes individuals feel autonomous, competent and socially respected, they are likely to enjoy the activity and continue their persistence.

Extrinsic motivators such as rewards or external pressures may not produce the same results for their incapacity to produce pleasure and enjoyment. Nevertheless, under certain conditions, they may become internalised and generate positive results. As mentioned above, social context has an essential role in determining the degree of internalization of external motivators. The more internalised the extrinsic motivation, the more autonomous the person will be when enacting the behaviours. Ryan and Deci (2000) offered a continuum representing the levels of internalization:

1. External regulation: This is when there is no autonomy and the individual acts as a result of external pressure or motivators which are beyond his/her control.

2. Introjected regulation: This is when an individual is moved by external causes but he/she experiences an internal urge to avoid shame or to maintain self-worth.

3. Identified regulation: This is when internal factors are stronger and the task or goal is personally valued and considered instrumentally significant by the individual.

4. Integrated regulation: This is when the external motivators are totally congruent with the individual's sense of self and are quite identical to intrinsic causes of action.

Self-determination theory association with the concept of self is interesting in that it presents individuals as agents of their own behaviours and actions rather than as passive subjects of external stimuli. Also, the complexity of traditional intrinsic/extrinsic dichotomy and the possible combination of them are highlighted in this theory.

\section{Self-Efficacy Theory}

As a highly influential theory, self-efficacy was established by Bandura $(1977,1997)$ within the social cognitive paradigm. Social cognitive theories consider human beings as proactive and self-regulating agents rather than passive and reactive to inner drives or external stimuli (Schunk\& Pajares, 2002). Achievement and functioning are viewed as the product of interaction between behaviour, cognitive, personal and environmental factors (Bandura, 1986).

Self-efficacy beliefs are people's perceptions of their ability to perform well on a given task. It concerns an individual's self-belief regarding their own abilities to succeed in a task. Bandura (1997) defined selfefficacy as "beliefs in one's capabilities to organise and execute the courses of action required to produce given attainments" (p. 3). It is different from self-concept and self-esteem in that it deals with perceptions of one's ability specific to a task without reference to interpersonal or intrapersonal comparisons (Pajares and Schunk, 2002). Also, self-efficacy is concerned with judgments of local and particular capabilities, whereas the other two terms include judgments of global and overall attributes (Bandura, 1997).

There are four factors that determine self-efficacy, namely: mastery experiences, vicarious experiences, verbal persuasion and emotional arousal (Bandura, 1997, p.195). Mastery experiences are the experiences of accomplishing similar tasks. Previous success enhances efficacy expectations and past failure lowers them. Vicarious experiences include the observation of other people's behaviour which could be identified as close models. The performance of models could impact efficacy in a similar fashion. Verbal persuasion can involve other people's judgements of one's ability to accomplish a task. Encouragement and feedback are among them. Emotional arousal includes feelings of stress and anxiety. If an individual feels stressed or anxious he/she may not perform well due to a decline in efficacy expectations (Bandura, 1997).

Self-efficacy beliefs are said to be significant factors in academic achievement and motivation (Schunk \& Pajares, 2005; Zimmerman, 2000). Greater efficacy results in more effort and persistence (Schunk, 2012). 
Besides, high sense of efficacy leads to setting higher and more challenging goals. People with robust selfefficacy believe that putting in more effort or using various strategies will lead to better results. Therefore, they are more optimistic about the future and are ready to expend a lot of time and energy on a given task (Flammer, 1995).

Special attention has been paid to the connection between self-efficacy, motivation and strategy use. Schunk (2012) insisted that learners with higher efficacy for learning are highly motivated to engage in academic activities by attending to instruction, rehearsing information, employing strategies to organise and make knowledge meaningful, and monitoring their own progress. Pintrich and De Groot (1990) and Kitsantas and Zimmerman (2009) also support the hypothesised connections among motivation, efficacy, and strategy use.

\section{Learned Helplessness}

Self-efficacy is the confidence about being able to do a task successfully, whereas learned helplessness is the opposite: a belief about the uncontrollability of events and outcomes (Shcunk, 2012; Woolfolk et al., 2003). Learned helplessness is a perceived independence between responses and outcomes (Seligman, 1975). If helplessness is generalised from a single experience to other experiences where events are potentially controllable, it becomes learned. Learned helplessness could possibly bring about passivity, loss of motivation, boredom and high levels of anxiety, and subsequently low academic performance (Alloy \& Seligman, 1979).

\section{Conclusion}

A review of the theories demonstrated that motivation research has undergone remarkable evolutions and developments. The apparent discrepancies seem to stem from the way different scholars looked at the issue from different angles. Thus, while scrutinising the same concept, they have come up with different conceptualisations and explanations. Because this abstract research agenda is still inaccessible via hypothesised models and descriptions, it is too complicated to reach a finalised consensus on the nature of motivation and the mechanisms through which it modifies choice and behaviour. However, a thorough understanding of the past trends and achievements would pave the way for future innovations.

\section{References:}

Alloy, L. A., \& Seligman, M. E. P. (1979). On the cognitive component of learned helplessness in animals and man. In G. Bower (Ed.), The psychology of learning and motivation (pp. 219-276). New York: Academic Press. https://doi.org/10.1016/s0079-7421(08)60084-5

Ames, C. (1992). Classrooms: Goals, structures, and student motivation. Journal of Educational Psychology, 84(3), $261-271$. https://doi.org/10.1037//0022-0663.84.3.261

Atkinson, J. W. (1957). Motivational determinants of risk-taking behaviour. Psychological Review, 64(6), $359-372$. http://doi.org/10.1037/h0043445

Bandura, A. (1977). Self-efficacy: Toward a unifying theory of behavioural change. Psychological Review, 84(2), 191-215. http://doi.org/10.1037/0033-295X.84.2.191

Bandura, A. (1997). Self-efficacy: The exercise of control. New York: Freeman. https://doi.org/10.1017/cbo9780511527692.003

Brophy, J. (1999). Research on motivation in education: Past, present, and future. In T. C. Urdan (Ed.), The role of context: Advances in motivation and achievement, (Vol. 11, pp.1-44). Stamford, CT: JAI.

Butler, R., \& Neuman, O. (1995). Effects of task and ego achievement goals on help-seeking behaviours and attitudes. Journal of Educational Psychology, 87, 261-271. https://doi.org/10.1037//0022-0663.87.2.261

Cantor, N., Markus, H. R., Niedenthal, P., \& Nurius, P. (1986). On motivation and the self-concept. In R. M. Sorrentino \& E. T. Higgins (Eds.), Handbook of motivation and cognition: Foundations of social behaviour (pp. 96-121). New York: The Guildford Press.

Covington, M. V. (1992). Making the grade: A self-worth perspective on motivation and school reform. Cambridge: Cambridge University Press. https://doi.org/10.1017/cbo9781139173582

Covington, M. V. (2000). Goal theory, motivation, and school achievement: An integrative review. Annual Review of Psychology, 51(1), 171-200. https://doi.org/10.1146/annurev.psych.51.1.171

Deci, E. L., \& Moller, A. C. (2005). The concept of competence: A starting place for understanding intrinsic motivation and selfdetermined extrinsic motivation. In A. J. Elliot, \& C. S. Dweck (Eds.), Handbook of competence and motivation (pp. 579597). New York: Guilford Press.

Deci, E. L., \& Ryan, R. M. (1985). Intrinsic motivation and self-determination in human behaviour. New York: Plenum Press. https://doi.org/10.1007/978-1-4899-2271-7

Deci, E. L., \& Ryan, R. M. (2000). The “what” and “why” of goal pursuits: Human needs and the self-determination of behaviour. Psychological Inquiry, 11(4), 227-268. https://doi.org/10.1207/s15327965pli1104_01

Eccles, J. S. (2007). Subjective task value and the Eccles et al. model of achievement related values. In A. J. Elliot \& C. S. Dweck (Eds.), Handbook of competence and motivation (pp. 105-121). London: The Guilford Press.

Eccles, J. S., \& Wigfield, A. (2002). Motivational beliefs, values, and goals. Annual Review of Psychology, 53(1), $109-132$. https://doi.org/10.1146/annurev.psych.53.100901.135153

Elliot, A. J., \& McGregor, H. A. (2001). A $2 \times 2$ achievement goal framework. Journal of Personality and Social Psychology, 80(3), 501-519. http://dx.doi.org/10.1037/0022-3514.80.3.501 
Elliot, A. J., \& Thrash, T. M. (2001). Achievement goals and the hierarchical model of achievement motivation. Educational Psychology Review, 13(2), 139-156. https://doi.org/10.1023/a:1009057102306

Flammer, A. (1995). Developmental analysis of control beliefs. In A. Bandura (Ed.), Self-efficacy in a changing society (pp. 69-113). New York: Cambridge University Press. https://doi.org/10.1017/cbo9780511527692.005

Greeno, J. G., Collins, A. M., \& Resnick, L. B. (1996). Cognition and learning. In D. C. Berliner, \& R. C. Calfee (Eds.), Handbook of Educational Psychology (pp. 15-46). New York: Macmillan.

Hareli, S., \& Weiner, B. (2002). Social emotions and personality inferences: A scaffold for a new direction in the study of achievement motivation. Educational Psychologist, 37(3), 183-193. https://doi.org/10.1207/s15326985ep3703_4

Kitsantas, A. \& Zimmerman, B. (2008) College students' homework and academic achievement: The mediating role of selfregulatory beliefs. Metacognition and Learning, 4, 97-110. https://doi.org/10.1007/s11409-008-9028-y

Kuhl, J. (2001). A functional approach to motivation. In A. Efklides, J. Kuhl, \& R. M. Sorrentino (Eds.), Trends and prospects in motivation research (pp. 239-268). Dordrecht, The Netherlands: Kluwer. https://doi.org/10.1007/0-306-47676-2_14

Kuhl, J., \& Blankenship, V. (1979). Behavioural change in a constant environment: Shift to more difficult tasks with constant probability of success. Journal of Personality and Social Psychology, 37(4), 549-561. https://doi.org/10.1037//00223514.37.4.551

Lemos, M. S. (2001). Context-bound research in the study of motivation in the classroom. In S. Volet, \& S. Jarvela (Eds.), Motivation in learning contexts: Theoretical advances and methodological implications (pp. 129-147). London: Pergamon.

Locke, E. A., \& Latham, G. P. (1990). A theory of goal setting and task performance. Englewood Cliffs, NJ: Prentice Hall.

Locke, E. A., \& Latham, G. P. (2002). Building a practically useful theory of goal setting and task motivation: A 35-year odyssey. American Psychologist, 57(9), 705-717. http://dx.doi.org/10.1037/0003-066X.57.9.705

Maslow, A. H. (1970). Motivation and personality $\left(2^{\text {nd }}\right.$ ed.). New York: Harper \& Row.

Oyserman, D., Bybee, D., \& Terry, K. (2006). Possible selves and academic outcomes: How and when possible selves impel action. Journal of Personality and Social Psychology, 91(1), 188-204. https://doi.org/10.1037/0022-3514.91.1.188

Pajares, F. \& Schunk, D. (2002). Self and self-belief in psychology and education: A historical perspective. In J. Aronson (Ed.), Improving academic achievement. New York: Academic Press. https://doi.org/10.1016/b978-012064455-1/50004-X

Park, Y. S., \& Kim, U. (1999). The educational challenge of Korea in the global era: The role of family, school, and government. Education Journal, 27(1), 91-120.

Pintrich, P. R. (2000). An achievement goal theory perspective on issues in motivational terminology, theory, and research. Contemporary Educational Psychology, 25(1), 92-104. https://doi.org/10.1006/ceps.1999.1017

Pintrich, P. R., \& De Groot, E. V. (1990). Motivational and self-regulated learning components of classroom academic performance. Journal of Educational Psychology, 82, 33-40. https://doi.org/10.1037//0022-0663.82.1.33

Pintrich, P. \& Schunk, D. (1996). Motivation in education: Theory, research \& applications. Englewood Cliffs, NJ: Prentice-Hall.

Pintrich, P. R., \& Schunk, D. H. (2002). Motivation in education: Theory, research, and applications (2 ${ }^{\text {nd }}$ ed.). Upper Saddle River, NJ: Pearson Education.

Ryan, R. M., \& Deci, E. L. (2000). Self-determination theory and the facilitation of intrinsic motivation, social development, and well-being. American Psychologist, 55(1), 68-78. https://doi.org/10.1037//0003-066x.55.1.68

Schunk, D. H. (1996). Goal and self-evaluative influences during children's cognitive skill learning. American Educational Research Journal, 33(2), 359-382. https://doi.org/10.3102/00028312033002359

Schunk, D. H. (2012). Learning theories: An educational perspective $\left(6^{\text {th }}\right.$ ed.). Boston: Pearson Education.

Schunk, D. H., \& Pajares, F. (2005). Competence perceptions and academic functioning. In A. J. Elliot \& C. S. Dweck (Eds.), Handbook of competence and motivation (pp. 85-104). New York: Guilford Press.

Seligman, M. E. P. (1975). Helplessness: On depression, development, and death. San Francisco: Freeman.

Urdan, T., \& Maehr, M. L. (1995). Beyond a two-goal theory of motivation: A case for social goals. Review of Educational Research, 65(3), 213-244. https://doi.org/10.3102/00346543065003213

Weiner, B. (1985). An attributional theory of achievement motivation and emotion. Psychological Review, 92(4), 548-573. https://doi.org/10.1037//0033-295x.92.4.548

Weiner, B. (1992). Human motivation: Metaphors, theories, and research. Newbury Park, CA: SAGE Publications.

Wigfield, A. (1994). Expectancy-value theory of achievement motivation: A developmental perspective. Educational Psychology Review, 6(1), 49-78. https://doi.org/10.1007/bf02209024

Wigfield, A., \& Eccles, J. S. (1992). The development of achievement task values: A theoretical analysis. Developmental Review, 12(3), 265-310. https://doi.org/10.1016/0273-2297(92)90011-p

Wigfield, A., \& Eccles, J. S. (2002). The development of competence beliefs, expectancies for success, and achievement values from childhood through adolescence. In A. Wigfield, \& J. S. Eccles (Eds.), Development of achievement motivation (pp. 91120). San Diego: Academic Press. https://doi.org/10.1016/b978-012750053-9/50006-1

Wigfield, A., \& Tonks, S. (2002). Adolescents' expectancies for success and achievement task values during the middle and high school years. In F. Pajares, \& T. Urdan (Eds.), Academic motivation of adolescents (pp. 53-82). Greenwich, CT: Information Age Publishing.

Wolters, C. A., Yu, S. L., \& Pintrich, P. R. (1996). The relation between goal orientation and students' motivational beliefs and selfregulated learning. Learning and Individual Differences, 8(3), 211-238. https://doi.org/10.1016/s1041-6080(96)90015-1

Woolfolk, A. E., Winne, P. H., \& Perry, N. E. (2003). Educational psychology (2 $2^{\text {nd }}$ ed.). Toronto: Pearson Education.

Zimmerman, B. J. (2000). Attaining self-regulation: A social cognitive perspective. In M. Boekaerts, P. R. Pintrich \& M. Zeidner (Eds.), Handbook of self-regulation (pp. 13-39). San Diego: Academic Press. https://doi.org/10.1016/b978-012109890$\underline{2 / 50031-7}$ 